\title{
A Study on an Operation Strategy of Dual-Infeed HVDC System
}

\author{
Chan-Ki Kim* and Gilsoo Jang ${ }^{\dagger}$
}

\begin{abstract}
This paper deals with the operation strategy of reactive power in a multi-infeed HVDC (MIHVDC) system, in which several converters are connected to the same or nearby separate AC buses. The potential problems concerning a MIHVDC system when feeding a weak AC network are as follows: the need for coordination of the recovery control, the possibility of voltage instability or low quality of the area connected to the MIHVDC system, and the risk of mutual commutation failures. These problems in MIHVDC systems are similar to those in single-infeed HVDC (SIHVDC) systems, but the differences with the phenomenon of the SIHVDC system are the interactions between converters. The main reason for the potential problems of HVDC systems (MIHVDC or SIHVDC) is voltage variation; therefore, to mitigate the voltage variations, the performances of the HVDC system should be enhanced. Consequently, to mitigate the potential problems of MIHVDC systems, several solutions are suggested in this study, including installing STATCOM and installing a line arrester on the tower. The study results will be applied to a multi-infeed HVDC system in Korea.
\end{abstract}

Keywords: HVDC, Multi-infeed HVDC, Line arrester, Voltage control

\section{Introduction}

Due to the wide application of high-voltage direct current (HVDC) transmission, many power systems consist of more than one HVDC converter infeeding into an alternating current (AC) network. Multi-infeed converters either share a common $\mathrm{AC}$ bus or are connected to buses that are electrically close. Common-mode interaction through an $\mathrm{AC}$ system disturbance (such as voltage distortion due to harmonics, phase unbalance due to a negative sequence, and amplitude and phase changing due to AC faults), can degrade the performance of each HVDC system. Additionally, the large amount of shunt compensation and number of filters tends to make the AC system resonant at a relatively low multiple of the fundamental frequency. The potential problems arising from a multi-infeed (MIHVDC) system in which several converters are connected to a weak $\mathrm{AC}$ system are as follows: high temporary overvoltage and risk of voltage/power instability, multiple commutation failures due to the interaction between HVDC links and transient $\mathrm{AC}$ voltage depression due to simultaneous recovery of HVDC links after AC faults. Therefore, for an MIHVDC system, the following criteria need to be fulfilled:

- Start up, shut down, and ramping of HVDC power transfer must not cause unacceptable voltage transient.

- Partial or total HVDC power cessation (load rejection) must not result in potentially damaging transient or sustained overvoltage.

$\dagger$ Corresponding Author: School of Electrical Engineering, Korea University, Korea. (gjang@korea.ac.kr)

* KEPCO Korea Electric Power Research Institute (KEPRI), Korea (chankikim@kepco.co.kr)

Received: March 1, 2016; Accepted: July 27, 2016
Several studies related to these problems have been performed [1] to [4]. The power/voltage stability of the MIHVDC system was studied in [1] and [2]; these studies were motivated by similar classical concerns about singleinfeed HVDC systems.

The purposes of this study are to examine the potential problems between HVDC Bipole 1 and Bipole 2 in Korea and to suggest a solution for these problems. In this paper, to mitigate the problems as stated above, several solutions are suggested, including installing STATCOM and installing a line arrester on a tower.

\section{System Study}

Jeju Island of Korea is located off the southern tip of the Korean Peninsula. Because the main industry of Jeju (Cheju) is tourism, and the rate of increasing power usage in Jeju is $7[\%]$ per year, an additional installation of a thermal power plant is not suitable from an environmental viewpoint. Therefore, two HVDCs were constructed in 1997 and 2012, respectively.

Because the Jeju network is connected by HVDC systems and has few thermal power plants, it is a relatively weak system from the viewpoint of stability. Additionally, because Jindo and Haenam in southern Korea are the last terminals in the electrical network of the mainland, the network around these terminals has local voltage stability and temporary overvoltage problems. Bipole 1 (Jeju-H/N (Haenam) HVDC) and Bipole 2 (Jeju-J/D (Jindo) HVDC) are connected to each other, and this system is a "multiinfeed HVDC". The distance between two converters on the mainland is approximately $50 \mathrm{~km}$ and approximately $20 \mathrm{~km}$ on the island. This distance is electrically close, 


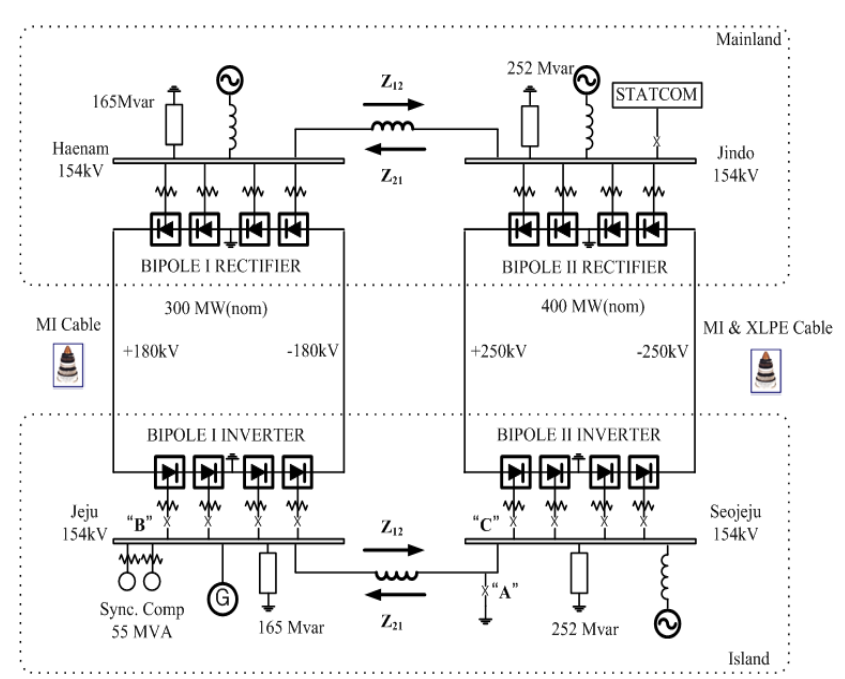

Fig. 1. HVDC system configuration on Jeju Island of South Korea

which means that the changes in the voltages at one converter busbar are reflected onto the busbar of another converter, and can result in interactions between the converters. Fig. 1 shows the multi-infeed HVDC with two bipoles in Korea.

\subsection{Contingencies and requirements of bipole 1 and bipole 2 HVDC}

The capacity of Bipole 1 is 150 [MW] $\times 2$, operated in bipole mode, and the configuration of Bipole 2 is a double monopole at $200[\mathrm{MW}] \times 2$. On Jeju Island, the total capacity of the two HVDC systems is 400 [MW]; these values are determined by considering the reliability $(\mathrm{N}-1)$ condition. Because the capacity of the HVDC systems is the largest in Jeju, the HVDC systems always operate in frequency control mode. Therefore, the cases that have been studied are based on contingencies and reliability. In this paper, the studied fault scenarios are as follows.

a. In frequency mode, power transfers between two HVDC systems must be possible. In the case where the Haenam (H/N) HVDC is tripped, the Jindo (J/D) HVDC system must transfer the HVDC total power to Jeju Island. Among the studied cases, the worst case is that when the $\mathrm{H} / \mathrm{N}$ HVDC has a power of 100 [MW], and the J/D HVDC has a power of 300[MW], the H/N HVDC is tripped, and the power of the J/D HVDC increases to 400 [MW].

b. The AC voltage must be limited according to HVDC blocking or a trip. For this problem the worst case is that in which the J/D HVDC system generates 400 [MW], and a trip or blocking occurs.

c. HVDC systems must endure AC network disturbances such as voltage distortions, AC faults, and the energizing of generators, transformers, and filters of nearby HVDCs.

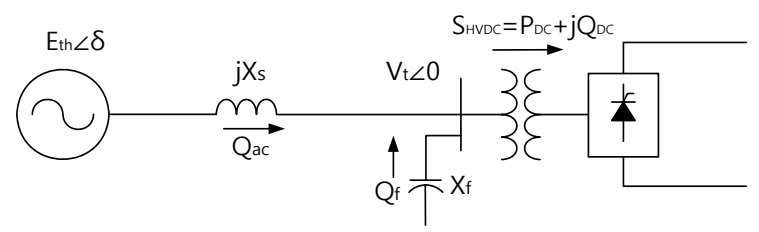

Fig. 2. Thevenin equivalent circuit of HVDC system

In this case, the maximum AC network disturbance is the energizing of an $\mathrm{AC}$ cable line, for which the rating is 84 [Mvar].

d. MIHVDC systems need to be robust to commutation failure. In an HVDC system, commutation failures are inevitable. However, in an MIHVDC system, the commutation processes influence each other and the failure in one inverter can result in a commutation failure in other converters because of the interactions.

e. An MIHVDC system must operate within the voltage stability region.

\subsection{Mathematical review of HVDC system and AC}

Fig. 2 shows the Thevenin equivalent circuit of an HVDC system, where XS is the Thevenin impedance, Eth is the Thevenin voltage in the condition that PDC is the DC power and QDC is the consumed reactive power of the HVDC. For DC shutdown or blocking, the AC side voltage (Vt in Fig. 2) will jump to the Thevenin voltage (Eth), whereby the Thevenin voltage in this case is, as stated above, temporary overvoltage (TOV), DOV, and FFTOV. Several methods to mitigate the overvoltage from Fig. 2 can be used. The first method is to reduce the Thevenin impedance, that is, to increase the effective SCC by installing a synchronous compensator. The second method is to reduce or regulate the AC side voltage with a reactive power compensator such as a static synchronous compensator (STATCOM), a static var compensator (SVC) or a shunt reactor. From Fig. 2, the $\mathrm{AC}$ system equations and $\mathrm{DC}$ system equations of the $\mathrm{AC}$ equivalent circuit are as follows:

$$
\begin{aligned}
& S_{H V D C}=P_{D C}+j Q_{D C}=V_{D C} I_{D C}=\frac{V_{t} E_{t h}}{\mathrm{X}_{\mathrm{s}}} \sin (\delta) \\
& Q_{D C}=P_{D C} \tan (\phi), \mathrm{ESCR}=\frac{S C C-Q_{f}}{P_{D C}}=\frac{1}{X_{e s c}}, Q_{f}=\frac{V_{t}^{2}}{\mathrm{Xf}} \\
& Q_{a c}=\frac{V_{t}\left(V_{t}-E_{t h} \cos (\delta)\right)}{\mathrm{X}_{\mathrm{s}}}, \cos (\phi)=\frac{\cos (\alpha)-\cos (\gamma)}{2} \\
& E_{t h} \angle \delta=V_{t}+\frac{X_{e s c} Q_{D C}}{V_{t}}+\frac{\mathrm{j} \mathrm{X}_{\mathrm{esc}} \mathrm{P}_{\mathrm{DC}}}{\mathrm{V}_{\mathrm{t}}} \\
& =\sqrt{\left(V_{t}+\frac{X_{e s c} Q_{D C}}{V_{t}}\right)^{2}+\left(\frac{X_{e s c} P_{D C}}{V_{t}}\right)^{2}} \angle_{\mathrm{atan}}\left(\frac{X_{e s c} P_{D C}}{V_{t}^{2}+X_{e s c} Q_{D C}}\right)
\end{aligned}
$$

From Eq. (1) to Eq. (3), SCC is the short circuit capacity 
of the AC system, $\mathrm{Q}_{\mathrm{ac}}$ is the reactive power consumed in the $\mathrm{AC}$ system, and $\mathrm{Q}_{\mathrm{f}}$ is the reactive power supplied by the filter. $\alpha$ is the firing angle, and $\gamma$ is the extinction angle in the HVDC system.

From Fig. 2 and Eqs. (1) and (3), the reactive power equation of an $\mathrm{AC} / \mathrm{DC}$ network system is presented in Eq. (4) and Eq. (5). As Eq. (4) represents the reactive power relation between the $\mathrm{AC}$ system and DC system in a steady state, $\mathrm{Q}_{\text {com }}$ is the reactive power capacity required in a steady state. In general, $\mathrm{QDC}$ is equal to $\mathrm{Q}_{\mathrm{f}}$, and $\mathrm{Q}_{\mathrm{ac}}$ is supplied by the reactive power compensator of the $\mathrm{AC}$ system. As Eq. (5) shows the required reactive power capacity in a transient state, $\mathrm{V}_{\text {limit }}$ is determined by the time inverse characteristics of HVDC protection.

\section{In steady state:}

$$
\mathrm{Q}_{\mathrm{com}}=\underbrace{\frac{\mathrm{V}_{\mathrm{t}}\left(\mathrm{V}_{\mathrm{t}}-\mathrm{E}_{\mathrm{th}} \cos (\delta)\right)}{\mathrm{X}_{\mathrm{s}}}}_{\text {Qac of AC Network } \mathrm{QDC}_{\mathrm{DC}} \text { of HVDC } \mathrm{Q}_{\mathrm{f}} \text { of HVDC Filter }}+\underbrace{\mathrm{P}_{\mathrm{DC}} \tan (\phi)}-\underbrace{\frac{\mathrm{V}_{\mathrm{t}}^{2}}{\mathrm{X}_{\mathrm{f}}}}
$$

\section{In transient state:}

$$
Q_{\text {dynamic }}\left(E_{\text {th }}-V_{\text {limit }}\right) \text { SCC for }_{V_{\text {limit }}}=\left\{\begin{array}{cc}
1.20[\mathrm{p} . \mathrm{u}] & 0.06[\mathrm{~s}] \\
1.14[\mathrm{p} . \mathrm{u}] & 0.30[\mathrm{~s}] \\
1.10[\mathrm{p} . \mathrm{u}] & 1.00[\mathrm{~s}] \\
1.037[\mathrm{p} . \mathrm{u}] & 19.0[\mathrm{~s}]
\end{array}\right.
$$

To investigate overvoltage in an MIHVDC system, if the single-infeed (SIHVDC) shown in Fig. 2 expands into an MIHVDC system, two converters are interconnected with each Thevenin impedance. This means that from the viewpoint of overvoltage, the blocking of one converter can cause overvoltage of another converter. By using [1] and [2], the Thevenin voltage of the MIHVDC system according to a converter blocking condition are shown in Eq. (6) and Eq. (7). In Eq. (6) and Eq. (7), $\Delta \mathrm{E}_{\mathrm{th} 2}=\mathrm{E}_{\mathrm{th} 2}-\mathrm{V}_{\mathrm{b} 2}$, $\Delta \mathrm{E}_{\mathrm{th} 1}=\mathrm{E}_{\mathrm{th} 1}-\mathrm{V}_{\mathrm{b} 1}, \mathrm{~V}_{\mathrm{b} 1}$, and $\mathrm{V}_{\mathrm{b} 2}$ are the initial values of each bus, $X_{c 1 n}$ and $X_{c 2 n}$ are the capacitances of $J / D$ and $H / N$, and $\mathrm{SCC} 1$ and $\mathrm{SCC} 2$ are the SCC of J/D and $\mathrm{H} / \mathrm{N}$, respectively, according to Table 1 .

$$
\begin{aligned}
& E_{t h 1}=V_{b 1}+\frac{X_{e s c 1} \cdot Q_{D C 1}}{V_{b 1}}+j \frac{X_{e s c 1} \cdot P_{D C 1}}{V_{b 1}}+M I I F_{12} \cdot \Delta E_{t h 2} \\
& E_{t h 2}=V_{b 2}+\frac{X_{e s c 2} \cdot Q_{D C 2}}{V_{b 2}}+j \frac{X_{e s c 2} \cdot P_{D C 2}}{V_{b 2}}+M I I F_{21} \cdot \Delta E_{t h 1}
\end{aligned}
$$

$E_{t h 1}=$

$\sqrt{\left(\frac{V_{b 1}^{2}+V_{b 1} \cdot M I I F_{12} \cdot \Delta E_{t h 2}+X_{e s c 1} \cdot Q_{D C 1}}{V_{b 1}}\right)^{2}+\left(\frac{X_{e s c 1} P_{D C 1}}{V_{b 1}}\right)^{2}}<\psi_{1}$

\begin{tabular}{|c|c|c|}
\hline & HVDC Bipole 1 & HVDC Bipole 2 \\
\hline Power rating & $150[\mathrm{MW}] \times 2$ (Bipoles) & $200[\mathrm{MW}] \times 2$ (Bipoles) \\
\hline Voltage & $180[\mathrm{kV}]$ & $250[\mathrm{kV}]$ \\
\hline Current & $840[\mathrm{~A}]$ & $800[\mathrm{~A}]$ \\
\hline $\begin{array}{c}\text { Firing angle } \\
\text { (Rectifier) }\end{array}$ & $23[\mathrm{deg}]-$ Alpha & $13[\mathrm{deg}]-$ Alpha \\
\hline $\begin{array}{c}\text { Firing angle } \\
\text { (Inverter) }\end{array}$ & 27 [deg] - Gamma & $23[\mathrm{deg}]-$ Gamma \\
\hline $\begin{array}{l}\text { Short Circuit Capacity } \\
\text { (SCC) } \\
\text { Multi Infeed Interaction } \\
\text { Factor (MIIF) }\end{array}$ & $\begin{array}{c}\text { H/N(Rectifier) : } \\
\text { 2793[MVA] } \\
\text { Worst Case : } \\
\text { 2372[MVA] } \\
\text { MIIF : } 0.412 \\
\end{array}$ & $\begin{array}{c}\text { J/D(Rectifier) : } \\
\text { 2199[MVA] } \\
\text { Worst Case : } \\
\text { 1957[MVA] } \\
\text { MIIF : } 0.52 \\
\end{array}$ \\
\hline Reactive POWER rating & $105[$ Mvar $] \times 2$ & $105[$ Mvar $] \times 2$ \\
\hline $\begin{array}{c}\text { Operating mode } \\
\text { (Rectifier) }\end{array}$ & Voltage control & Current control \\
\hline $\begin{array}{c}\text { Operating mode } \\
\text { (Inverter) }\end{array}$ & Current control & Voltage control \\
\hline $\begin{array}{c}\text { Minimum gamma } \\
\text { in inverter }\end{array}$ & $9[\mathrm{deg}]$ & $9[\mathrm{deg}]$ \\
\hline $\begin{array}{c}\% \text { impedance of } \\
\text { transformer }\end{array}$ & $12[\%]$ & $15[\%]$ \\
\hline Smoothing reactor & $60[\mathrm{mH}]$ & $60[\mathrm{mH}]$ \\
\hline
\end{tabular}

$E_{\text {th2 }}=$

$\sqrt{\left(\frac{V_{b 2}^{2}+V_{b 2} \cdot M I I F_{21} \cdot \Delta E_{t h 1}+X_{e s c 2} \cdot Q_{D C 2}}{V_{b 2}}\right)^{2}+\left(\frac{X_{e s c 2} P_{D C 2}}{V_{b 2}}\right)^{2}}<\psi_{2}$
Table 1. Rating of HVDC Bipole 1 and HVDC Bipole 2

where,

$X_{e s c 1}[p . u]=.\frac{j X_{s c 1}[p . u .] \cdot\left(-j X_{c 1 n}[p . u .]\right)}{-j\left(X_{c 1 n}[p . u .]-X_{s c 1}[p . u .]\right)}$

$X_{\text {esc2 }}$ [p.u.] $=\frac{j X_{\text {sc2 }} \text { [p.u.] } \cdot\left(-j X_{c 2 n}[\text { p.u.] })\right.}{-j\left(X_{c 2 n}\left[\text { p.u.] }-X_{s c 2}[\text { p.u. }]\right)\right.}$

$\mathrm{X}_{\text {esc1 }}$ [p.u.]

$$
=\frac{j \frac{P_{D C 1}+M_{I I F} \cdot P_{D C 2}}{S_{12}}[\text { p.u. }] \cdot\left(-j X_{c 1 n}[\text { p.u. }]\right)}{-j\left(X_{c 1 n}[\text { p.u. }]-\frac{\left.P_{D C 1}+M_{I I F} \cdot P_{D C 2}[\text { p.u. }]\right)}{S_{12}}\right.}
$$

$\mathrm{X}_{\mathrm{esc} 2}$ [p. u. ]

$$
=\frac{j \frac{P_{D C 2}+M_{I I F} \cdot P_{D C 1}}{\mathrm{SCC}_{2}}[\text { p.u. }] \cdot\left(-j X_{c 2 n}[\text { p.u. }]\right)}{-j\left(X_{c 2 n}[\text { p.u. }]-\frac{P_{D C 2}+M_{I I F} \cdot P_{D C 1}}{S_{21}}[\text { p.u. }]\right)}
$$

$\Psi_{1}=\operatorname{atan}\left(\frac{\mathrm{X}_{\mathrm{esc} 1} \mathrm{P}_{\mathrm{DC} 1}}{\mathrm{~V}_{\mathrm{b} 1}^{2}+\mathrm{V}_{\mathrm{b} 1} \cdot \mathrm{MIIF}_{12} \cdot \Delta \mathrm{E}_{\mathrm{th} 2}+\mathrm{X}_{\mathrm{esc} 1} \mathrm{Q}_{\mathrm{DC} 1}}\right)$

$\Psi_{2}=\operatorname{atan}\left(\frac{\mathrm{X}_{\mathrm{esc} 2} \mathrm{P}_{\mathrm{DC} 2}}{\mathrm{~V}_{\mathrm{b} 2}^{2}+\mathrm{V}_{\mathrm{b} 2} \cdot \mathrm{MIIF}_{21} \cdot \Delta \mathrm{E}_{\mathrm{th} 1}+\mathrm{X}_{\mathrm{esc} 2} \mathrm{Q}_{\mathrm{DC} 2}}\right)$

\section{Case Study}

\subsection{Temporary overvoltage and power transfer at sudden load variations}

Changes in the reactive power balance of the $\mathrm{AC}$ network initiated by switching, faults, or power flow variation, either in AC or DC systems, produce change in the operating voltages. A surplus in reactive power leads to 
Table 2. Overvoltage and resonance frequency according to HVDC operation modes (initial voltage: 1.03 [p.u] for H/N, $1.026[\mathrm{p} . u]$ for $\mathrm{J} / \mathrm{D})$

\begin{tabular}{c|c|c|c|c|c|c|c|c|c|c}
\hline & $\begin{array}{c}\mathrm{H} / \mathrm{N} \\
\text { Converter }\end{array}$ & $\begin{array}{c}\mathrm{J} / \mathrm{D} \\
\text { Converter }\end{array}$ & $\begin{array}{c}\text { SCR } \\
(\mathrm{H} / \mathrm{N})\end{array}$ & $\begin{array}{c}\text { SCR } \\
(\mathrm{J} / \mathrm{D})\end{array}$ & $\begin{array}{c}\text { Resonance } \\
(\mathrm{H} / \mathrm{N})\end{array}$ & $\begin{array}{c}\text { Resonance } \\
(\mathrm{J} / \mathrm{D})\end{array}$ & $\begin{array}{c}\text { Overvoltage } \\
(\mathrm{H} / \mathrm{N})\end{array}$ & $\begin{array}{c}\text { Overvoltage } \\
(\mathrm{J} / \mathrm{D})\end{array}$ & $\begin{array}{c}\text { Overvoltage } \\
(\mathrm{H} / \mathrm{N})\end{array}$ & $\begin{array}{c}\text { Overvoltage } \\
(\mathrm{J} / \mathrm{D})\end{array}$ \\
\cline { 6 - 10 }
\end{tabular}

voltage increases and larger disturbances result in temporary overvoltages. In an HVDC system, thyristor current-source converters always consume reactive power in the order of $0.5[\mathrm{p} . \mathrm{u}]$ of the DC power. For a weak system, a sudden load rejection (e.g., one caused by a fault in the other end of the transmission or a commutation failure), will lead to temporary overvoltages. It is possible to estimate the overvoltages at load rejection with simple formulas.

\subsubsection{Worst temporary overvoltage case:}

Assume the case of changing the HVDC power from $400[\mathrm{MW}]$ to $0[\mathrm{MW}]$ according to HVDC blocking:

Initial conditions: HVDC power rejection $=400[\mathrm{MW}]$,

$$
\begin{aligned}
S C R & =\frac{2199[M V A]}{400[M W]}=5.49, P_{D C}=1[p \cdot u], Q_{D C} \\
& =0.505[p \cdot u], V_{t}=1.026[p \cdot u], E_{t h}=114 \angle 9.9^{0}
\end{aligned}
$$

Calculation 1): AC network operating upper limit: 164 $[\mathrm{kV}]$

$$
\begin{aligned}
Q_{\text {dynamic }} & =\left(E_{\text {th }}-V_{\text {limit }}\right) S C C \\
& =((1.114-1.065)) 2199=108[\text { Mvar }]
\end{aligned}
$$

Calculation 2): AC GIS protection setting value: 169 $[\mathrm{kV}]$

$$
\begin{aligned}
Q_{\text {dynamic }} & =\left(E_{t h}-V_{\text {limit }}\right) S C C \\
& =((1.114-1.098)) 2199=35.2[\text { Mvar }]
\end{aligned}
$$

\subsubsection{Worst power transfer case:}

In the case of a power transfer in which changes of HVDC power are $100[\mathrm{MW}$ ] to $400[\mathrm{MW}$, the required reactive power capability is calculated as follows in steady state:

\section{Initial conditions:}

$$
\begin{aligned}
& P_{D C}=0.25[p . u]=100[M V], \\
& Q_{D C}=0.3 \times 0.25[p . u],
\end{aligned}
$$

$$
\begin{aligned}
& Q_{a c}=0.128[p . u], V_{t}=1.026[p . u] \\
& \begin{aligned}
Q_{\text {com }} & =Q_{a c}+Q_{D C}-Q_{f} \\
& =0.128[p . u]+0.075[p . u]-0.075[p . u] \\
& =0.128[\mathrm{p} \cdot \mathrm{u}]
\end{aligned}
\end{aligned}
$$

Calculation: In contrast, in the case whereby the power of the HVDC system is increased from 0.25 [p.u] to $1[\mathrm{p} . \mathrm{u}]$, the reactive power unbalance is calculated as follows in a power transfer state:

$$
\begin{aligned}
Q_{\text {com }} & =\Delta Q_{a c}+\Delta Q_{D C}-Q_{f} \\
& =0.472[p . u]+0.5[p . u]-0.5[p . u] / 0.075[p . u] \\
& =0.472[p . u] / 0.897[\mathrm{p} . \mathrm{u}]
\end{aligned}
$$

Finally, the required reactive power capability is simply as follows:

$$
Q_{\text {com }}=0.472[p . u] \times 400[M W]=188.8[\text { Mvar }]:
$$

with additional filters

$$
Q_{\text {com }}=0.897[p . u] \times 400[M W]=358.8[\text { Mvar }]:
$$

without additional filters

\subsection{Low-order resonance in MIHVDC:}

In the case in which an HVDC system is connected to a weak AC system, the possibility occurs of low - order resonance between the AC network and the filters and shunt banks. The resonance frequency is therefore determined by the relationship between the capacitance of the HVDC and the Thevein impedance. Therefore, the method used to calculate the low order resonance frequency in each converter of the MIHVDC system is as follows:

$$
\begin{aligned}
& Z_{S C C i}=\frac{V_{a c}^{2}}{S C C_{i}}=\frac{V_{a c}^{2}}{P_{d i} \cdot M I S C R_{i}+M I I F F_{j i} \cdot M I S C R_{i} \cdot P_{d i}} \\
& L_{S C C i}=\frac{Z_{S C C i}}{2 \cdot \pi \cdot f}, \Delta Q_{H V D C i}=\text { Filter } \cdot \Delta P_{d i}, Z_{c i}=\frac{V_{a c}^{2}}{\Delta Q_{H V D C i}} \\
& C_{\text {Reactive }}=\frac{1}{2 \cdot \pi \cdot f \cdot Z_{c i}}, \omega_{r}=\omega_{0} \cdot \frac{1}{\sqrt{L_{S C C i} \cdot C_{\text {Reactive }}}}
\end{aligned}
$$


where $Z_{\text {sci }}$ is the Thevenin impedance in the voltage bus, $\Delta \mathrm{Q}_{\mathrm{HVDCi}}$ is the reactive power of the capacitor according to the $\mathrm{DC}$ power in the voltage bus, and $\Delta \mathrm{P}_{\mathrm{di}}$ is the $\mathrm{DC}$ power related to the filter switching in the voltage bus.

Table 2 shows the overvoltage calculated from Eq. (7) and the resonance point calculated in Eq. (8).

\subsection{Commutation failures}

In an MIHVDC system environment, the commutation failures of one converter from an $\mathrm{AC}$ fault may induce commutation failures of a nearby converter, despite the fact that an individual AC fault should not have induced commutation failures. Phase shift, voltage dip, and misfiring of the valves due to voltage distortion are events that cause commutation failure in a remote converter. As with a commutation failure, the AC fault recovery of a link in isolation is dictated in part by the ESCR of the inverter $\mathrm{AC}$ bus. With another link electrically nearby, the fault recovery is not only influenced by the strength of the bus, but also by the recovery characteristics of the other HVDC system. This quantifies the susceptibility of the converter to a commutation failure to calculate the maximum permissible balanced voltage drop $\Delta \mathrm{V}$ on the AC busbar of the converter. That is, a voltage drop of more than the amount shown in Eq. (8) can cause a commutation failure.

$$
\Delta \mathrm{V}=1-\frac{I_{d}^{\prime}}{\mathrm{I}_{\mathrm{d}}} \cdot \frac{\left(\mathrm{I}_{\mathrm{d}} / \mathrm{I}_{\mathrm{dFL}}\right) \cdot \mathrm{X}_{\mathrm{cpu}}}{\left(\mathrm{I}_{\mathrm{d}} / \mathrm{I}_{\mathrm{dFL}}\right) \cdot \mathrm{X}_{\mathrm{cpu}}+\cos \gamma_{0}-\cos \gamma}
$$

where Id is the prefault DC current, $\mathrm{I}_{\mathrm{d}}$ is the postfault DC current, $\mathrm{I}_{\mathrm{dFL}}$ is the nominal current, $\mathrm{X}_{\mathrm{cpu}}$ is the transformer percentage impedance, $\gamma$ is the operation extinction angle, and $\gamma_{0}$ is the absolute minimum extinction angle at which commutation fails. From Eq. (9) and Table 1, the commutation failure possibility index (CFPI) of Jeju Island for Bipole 1 is 0.538 and for Bipole 2 is 0.309 .

This means that Bipole 1 and Bipole 2 are very weak for commutation failures and need a number of countermeasures. By using the CFPI of Bipole 1 and Bipole 2,

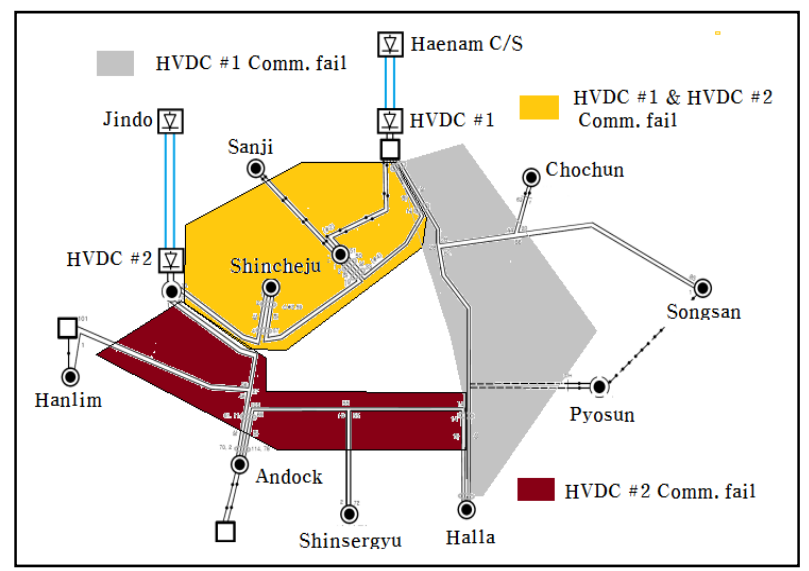

Fig. 3. Voltage contour map for commutation failure the voltage contour map for the commutation failure on Jeju Island is shown in Fig. 3. Fig. 3 shows a CFI contour map of Jeju Island based on the CFI of Bipole 1 and Bipole 2. Three areas are shown in Fig. 3, which are the Bipole 1 commutation failure area, the Bipole 2 commutation failure area, and the Bipole 1 and Bipole 2 simultaneous commutation failure area. Table 2 shows the overvoltage and the resonance frequency of Jindo $\mathrm{AC}$ network (J/D) and Haenam AC network $(\mathrm{H} / \mathrm{N})$ according to the HVDC operation modes. As the total maximum powers of Haenam and Jindo converters is $400 \mathrm{MW}$, both converter stations could have 4 operation modes (100MW/300MW, 300MW/ 100MW, 200MW/200MW, and 0MW/400MW). Therefore, the short circuit ratio $\left(\mathrm{SCR}=\frac{A C \text { network Capability }}{D C \text { Power }}\right)$ and resonance frequency $\left(\omega_{r}=\frac{1}{\sqrt{L C}}=\omega_{0} \cdot \sqrt{\frac{S C R}{0.6}}\right)$ are determined for each operation mode. Also, the overvoltage, for the cases that one of the two converters is tripped and both converters are tripped, are calculated.

\section{Review of Results and Countermeasures}

\subsection{Impact of overvoltage}

The overall design of the entire HVDC scheme is based on the specified voltage. The rated voltage is $154[\mathrm{kV}]$, and the full range of the voltage is from $139[\mathrm{kV}]$ to $164[\mathrm{kV}]$ within the operating limit voltage of $164[\mathrm{kV}]$. Operation beyond the specified range would mean that there is an insufficient tap range to allow for the converter to operate as designed. The HVDC system equipment that may be affected by the constant excessive voltage up to $170[\mathrm{kV}]$ during DC power transfer is as follows.

First, the thyristors in the valve have a built-in margin, as they are designed to withstand the voltage as determined by the protective voltage level of the valve surge arresters, which will not be affected, since the valve winding voltage remains within the design range.

Second, similar to all the other HVDC equipment, the transformer is designed for operation with the maximum AC voltage (in this paper, $164[\mathrm{kV}]$ ). The main risk of damage to the transformer from operation at an elevated voltage is excessive heating of the core. Additionally, the life step of the tap changer of the transformer is 0.8 millionstep. However, because the passive reactive devices such as the reactor and capacitor were operated by a mechanical switch that moves slowly, and simply operates the on-off control, the tap operation occurs frequently according to the voltage variation. In this case, the life-time of the tap changer is reduced.

Third, if the system voltage is increased above the design voltage $(164[\mathrm{kV}])$, the firing angle would need to be adjusted to keep the DC voltage constant. The adjustment of the firing angle over the range of operation 
of the converter would significantly increase the harmonic current generated by the thyristor valves. Such an increase in harmonic current generation would have two effects as follows.

- The voltage and current distortion on the $154[\mathrm{kV}]$ system would increase, with the result being above the specified limits.

- The increased harmonic current would increase the loading on the harmonic filters. The main concern is the number of harmonic filter resistors, which would be significantly overloaded and liable to overheating and failure. The increased harmonic loading on the capacitors and reactors would also reduce their lifetimes.

Fourth, for the main $154[\mathrm{kV}]$ filter capacitors, the majority of the voltage rating is due to the fundamental frequency voltage. Any increase in the system voltage would directly cause an overload of these capacitors, which would increase their failure rate. Additionally, the current rating of the reactors depends on both the harmonic and the fundamental frequency current rating; any increase would increase the reactor temperature which would reduce their lifetimes.

Fifth, the auxiliary supply equipment of an HVDC system is designed for $220 / 380[\mathrm{~V}],+10[\%]$ to $-15[\%]$ of the rated voltage. Overvoltages on the auxiliary system would cause premature failure of equipment and may cause operation of overload protection.

\subsection{Design of statcom and performance evaluation}

Comparing STATCOM with another reactive power compensator, it is observed that STATCOM has the following advantages. Firstly, in order to save the capacitors and reactors, the possibility of resonance at some critical operating condition can be reduced. Secondly, reactive power can be controlled continuously and precisely because of the fast control characteristics. Thirdly, the low inrush current reduces the impact on the AC network. Because of these advantages, STATCOM as a reactive power compensator was determined in the MIHVDC system. The highest temporary overvoltage (TOV) at the inverter AC network during permanent DC blocking is 1.12 [p.u] with fixed capacitors and filters connected. A dynamic compensator of 200 [Mvar] inductive can increase the TOV to 1.04[p.u] without the need to switch the filters. The capacitive rating of the compensators to fully compensate for the reactive power requirement during the power transfer is 200 [Mvar]. Therefore, in this paper, the combination of STATCOM $\pm 150[$ Mvar] and a shunt reactor of 30 [Mvar] $\times 5$ will meet the above requirements. The requirements for the STATCOM design are as follows.

- An HVDC system must be operated within the specified AC voltage range from $139[\mathrm{kV}]$ to $164[\mathrm{kV}]$, except for the voltage instability. In addition, the limit of the AC

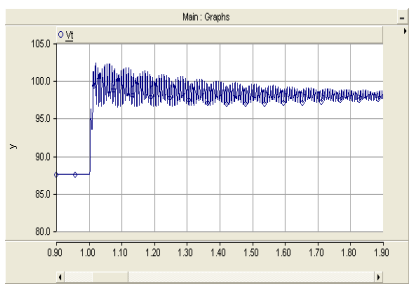

(a)

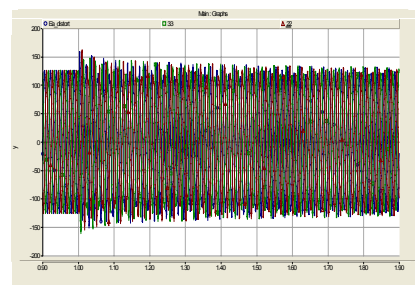

(b)

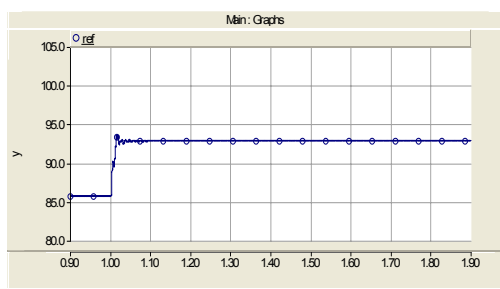

(c)

Fig. 4. Temporary overvoltage due to HVDC blocking

voltage is $164[\mathrm{kV}]$.

- Because STATCOM (spinning reserve reactive power equipment) is very expensive, the size must be reduced as much as possible.

- The combination between STATCOM and the shunt reactor is economical.

- The sizes of the shunt reactors must be uniform and determined by the switching voltage of the shunt reactor, which is dependent on the AC network impedance. The individual size of each shunt reactor is 30 [Mvar].

- The number of shunt reactors must be determined by considering reliability $(\mathrm{N}-1)$.

Fig. 4 shows the case of the sudden load rejection which leads to a temporary overvoltage due to HVDC blocking. From Fig. 4(a), as the main voltage resonance frequency is approximately at the 3rd harmonic, this frequency is determined by the equivalent Thevenin reactance and the capacitance, if the passive reactive power supplier of the HVDC is modeled as a simple capacitor. Since Fig. 4(b) shows the instantaneous voltage waveform (comparing the distorted waveform (including the 3rd harmonic) with the reference waveform in a transient state (dark circle)), the angle between phases is not constant, but is found. Because of this, the margin angle in the case of determining the HVDC operating angle, and the kick control, which increases the commutation angle temporarily, needs to be considered. As shown in Fig. 4(c), the simulation results in the case whereby the passive reactive power suppliers are not simple capacitors but are actual filters with damping resistors and reactors. The harmonic frequencies shown in Fig. 4(a) are not shown in Fig. 4(c), because that filter absorbs the harmonics in a transient state.

Fig. 5 shows the RMS AC voltage waveform, which shows the dynamic performance of an AC/DC network with STATCOM. Figs. 5(a) and 5(c) show the simulation results of the case without STATCOM, and Figs. 5(b) 


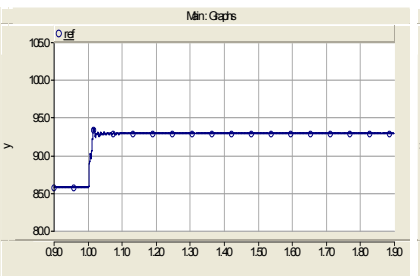

(a) HVDC blocking without STATCOM

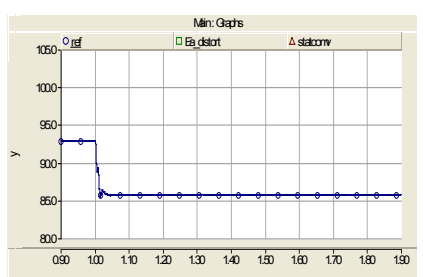

(c) Load increase without STATCOM

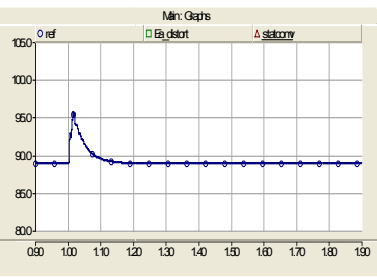

(b) with STATCOM

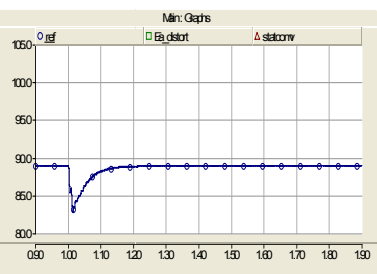

(d) with STATCOM
Fig. 5. AC RMS voltage waveforms for dynamic performance of STATCOM

and 5(d) show the results of the case with STATCOM. Additionally, Figs. 5(a) and 5(b) show the case of the temporary overvoltage due to HVDC blocking (400 [MW] $\Rightarrow 0[\mathrm{MW}]$ ), and Figs. 5(c) and 5(d) show the case of the sudden load increase $(100[\mathrm{MW}] \Rightarrow 400[\mathrm{MW}])$. In this case, the STATCOM capacity is $\mp 150$ [MVar].

\subsection{Installation of line arresters on tower at inverter side}

The main reason for commutation failures in an HVDC system is AC voltage reduction caused by lightning strikes. The incidence of lightning strikes on transmission lines is a very serious problem as it can produce dangerous overvoltage and power supply interruption. Transmission lines are normally protected with overhead ground wires. For properly designed lines, most lightning strikes on lines are expected to terminate on the ground wires. However, if the tower footing resistance is high, there is a high probability of insulation failure following a back flashover. The probability of an occurrence of insulation flashover can be reduced in two ways: by reducing the tower footing resistance and by installing a surge arrester. Fig. 6(a) shows the operation mechanism and waveform of operation time of the transmission line surge arresters (TLSAs). Normally, the clearing time of the transmission line faults is approximately six cycles, but the clearing time for a transmission line with a line arrester is 0.5 cycles. Because the tower footing resistance of the Jeju AC network is high because of the volcanic nature of the island, one solution to reduce a commutation failure is to install a surge arrester. Fig. 6 shows the performance test (Figs. 6 (b) and (c)) and simulation waveforms (Fig. 6 (d)) of a line arrester. In Fig. 6 , the condition of simulation is a lighting stroke on aphase at $1.0[\mathrm{sec}]$. Even though the AC voltage waveform

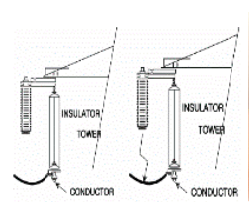

(a)

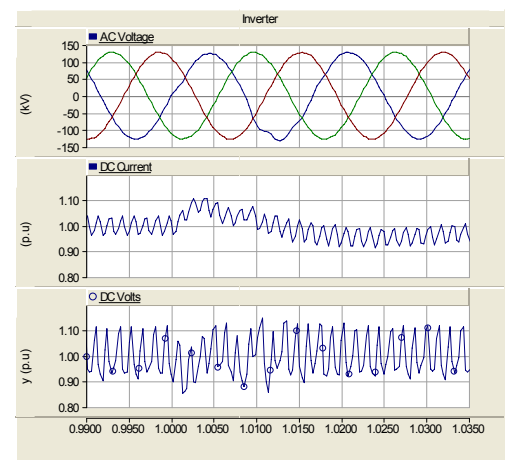

(d)

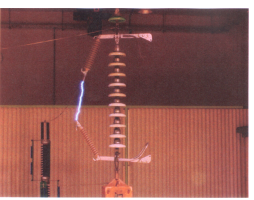

(b)

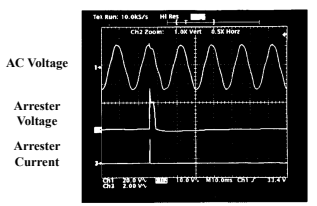

(c)
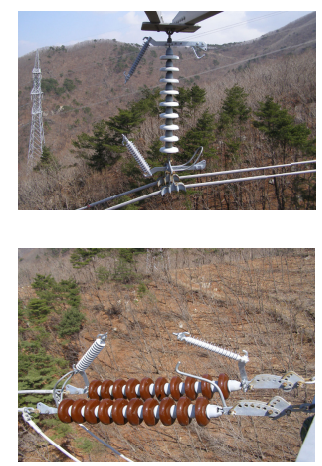

(e)

Fig. 6. Performance test and simulation of a line arrester: (a) Operation mechanism; (b) Testing; (c) Test waveform; (d) Simulation waveform (AC voltage, DC current, and DC voltage); (e) Field installation figure

shown in Fig. 6(c) is slightly distorted, a commutation failure is not generated. From this phenomenon, it is confirmed that a line arrester is robust for commutation failure in the inverter side.

\section{Conclusions}

This paper presents a reactive power managing method and criterion in an MIHVDC system, which is HVDC Bipole 1 and Bipole 2 in Korea. The technical approaches used in this study include steady state calculation, transient simulation, and the MAP method. As the main issues of the target system are overvoltage, commutation failures, and reactive power deficiency at the power transfer between HVDC converters, STATCOM and a line arrester are installed on the AC network. The suggested methods were confirmed by PSCADS/EMTDC simulation and may be used as a general guideline for MIHVDC system studies.

\section{Acknowledgements}

This work was partly supported by the Power Generation \& Electricity Delivery Core Technology Program of the Korea Institute of Energy Technology Evaluation and Planning (KETEP) granted financial resource (No. 20131020000100), and by the National Research Foundation of Korea (NRF) grant funded by the Korea government (MSIP) (No. NRF-2013R1A2A2A01067762). 


\section{References}

[1] Aik D.L.H, Andersson G., "Voltage stability analysis of multi-infeed HVDC systems," IEEE Transactions on Power Delivery, vol. 12, Issue 3, pp. 1309-1318, 1997

[2] Aik D.L.H, Andersson, G., "Power stability analysis of multi-infeed HVDC systems," IEEE Transactions on Power Delivery, vol. 13, Issue 3, pp. 923-931, 1998

[3] Karawita C., Annakkage U.D., "Multi-infeed HVDC interaction studies using small-signal stability assessment," IEEE Transactions on Power Delivery, vol. 24, Issue 2, pp. 910-918, 2009

[4] Aik D. L. H., Andersson G., "Use of participation factors in modal voltage stability analysis of multiinfeed HVDC systems," IEEE Transactions on Power Delivery, vol. 13, Issue 1, pp. 203-211, 1998

[5] Yang W. D., Xu Z., Han Z. X., "Co-ordinated hierarchical control strategy for multi-infeed HVDC systems," IEE Proceedings on Generation, Transmission and Distribution, vol. 149, Issue 2, pp. 242248, 2002

[6] Rahimi E., Gole A. M., Davies J. B., Fernando I. T., Kent K.L., "Commutation failure analysis in multiinfeed HVDC systems," IEEE Transactions on Power Delivery, vol. 26, Issue 1, pp. 378-384, 2011

[7] Aik D. L. H., Andersson G., "Analysis of Voltage and Power Interactions in Multi-Infeed HVDC Systems," IEEE Transactions on Power Delivery, vol. 28, Issue 2, pp. 816-824, 2013

[8] Chen, X, Gole A.M., MinXiao H, "Analysis of mixed inverter/rectifier multi-infeed HVDC systems," IEEE Transactions on Power Delivery, vol. 27, Issue 3, pp. 1565-1573, 2012

[9] Reeve J., Lane-Smith S. P., "Multi-infeed HVDC transient response and recovery strategies," IEEE Transactions on Power Delivery, vol. 8, Issue 4, pp. 1995-2001, 1993

[10] Liu C, Zhang B, Yunhe H, Wu F.F., Yingshang L, "An improved approach for AC-DC power flow calculation with multi-infeed DC systems," IEEE Transactions on Power Systems, vol. 26, Issue 2, pp. 862-869, 2011

[11] Arnold R., "Solutions to the power quality problem," Power Engineering Journal, vol. 15, Issue 2, pp. 6573, 2001

[12] Bozhko S.V., Blasco-Gimenez R., Risheng Li, Clare J. C., Asher G. M., "Control of offshore DFIG based wind farm grid with line-commutated HVDC connection," IEEE Transactions on Energy Conversion, vol. 22, Issue 1, pp. 71-78, 2007

[13] Nayak O.B., Gole A.M., Chapman D.G., Davies J.B., "Dynamic performance of static and synchronous compensators at an HVDC inverter bus in a very weak AC system," IEEE Transactions on Power
Systems, vol. 9, Issue 3, pp. 1350-1358, 1994

[14] Gole A.M., Sood V.K., "A static compensator model for use with electromagnetic transients simulation programs," IEEE Transactions on Power Delivery, vol. 5, Issue 3, pp. 1398-1407, 1990

[15] Li K, Liu J, Wang Z, Wei B, "Strategies and operating point optimization of STATCOM control for voltage unbalance mitigation in three-phase threewire systems," IEEE Transactions on Power Delivery, vol. 22, Issue 1, pp. 413-422, 2007

[16] Tarasiewics E.J., "Transmission line arrester energy, cost, and risk of failure analysis for partially shielded transmission lines," IEEE Trans. on Power Delivery, vol. 15, Issue 3, 2000.

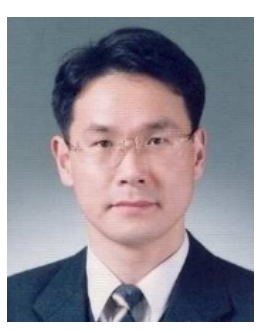

Chan-Ki Kim He obtained his M.Sc. and Ph.D. degrees in Electrical Engineering from Chung-Ang University, Korea in 1993 and 1996, respectively. Since 1996, he has been with KEPRI, the R\&D center of KEPCO (Korea Electric Power Corporation). His research interests are HVDC, Power Electronics and Generator Control.

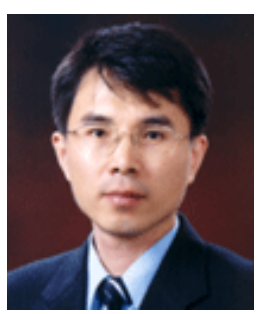

Gilsoo Jang He received his M.S. and $\mathrm{Ph} . \mathrm{D}$. from Korea University in 1994 and Iowa State University in 1997, respectively. Currently, he is a professor of the School of Electrical Engineering, Korea University. His research interests are power quality and power system control. 